Gerión. Revista de Historia Antigua

ISSN: 0213-0181

http://dx.doi.org/10.5209/geri.68587

\title{
La alimentación en las unidades domésticas campesinas a partir de las Metamorfosis de Ovidio ${ }^{1}$
}

\author{
$\mathrm{M}^{\mathrm{a}}$ Juana López Medina ${ }^{2}$
}

Recibido: 3 de abril de 2019 / Aceptado: 8 de octubre de 2019

Resumen. Las Metamorfosis de Ovidio ofrecen la posibilidad de aproximarnos a la alimentación de la sociedad romana, y en especial de las unidades domésticas campesinas, que forman el grueso de la población en el Alto Imperio. Para ello, se analiza principalmente el episodio de Baucis y Filemón. Su confrontación con otros mitos donde se ofrecen convivia, como el de la boda de Perseo y Andrómeda y el que Anio da a Eneas y sus compañeros, va a permitir también profundizar en el uso de la mitología para legitimar y reproducir las desigualdades sociales.

Palabras clave: campesinado; alimentación; desigualdades sociales; mitología; Ovidio.

\section{[en] Food in the Peasant Domestic Units from Ovid's Metamorphoses}

Abstract. Ovid's Metamorphoses offer the possibility of approaching the diet of Roman society, and especially of the peasant domestic units, as these compose the largest part of the population in the High Empire. For this, the episode of Baucis and Philemon is mainly analyzed. This contrasts with other myths where convivia are offered, such as the wedding of Perseus and Andromeda and the one in which Anius gives to Aeneas and his companions. These will also allow us to analyze the use of mythology to legitimize and reproduce social inequalities.

Keywords: Peasant; Food; Social inequalities; Mythology; Ovid.

Sumario: 1. Introducción: las unidades domésticas campesinas y las Metamorfosis de Ovidio. 2. Los alimentos en las Metamorfosis y las unidades domésticas campesinas. 3. Alimentación, desigualdades sociales y austeridad en las Metamorfosis. 4. Conclusiones. 5. Referencias bibliográficas.

Cómo citar: López Medina, $\mathrm{M}^{\mathrm{a}} \mathrm{J}$. (2020): La alimentación en las unidades domésticas campesinas a partir de las Metamorfosis de Ovidio, en Gerión 38/1, 117-135.

\footnotetext{
1 El presente trabajo se desarrolla dentro del marco del Grupo de Investigación ABDERA (HUM 145 PAIDI) y del Campus de Excelencia Internacional CeiPatrimonio. Forma parte del proyecto de investigación "Paisajes de la Hispania romana (2): modelos de gestión de los recursos en un marco provincial en transición (II ANE - V DNE)" (HAR2017-87488-R, MINECO).

2 Universidad de Almería.

Código ORCID 0000-0003-3123-3969.

E-mail: jlmedina@ual.es
} 


\section{Introducción: las unidades domésticas campesinas y las Metamorfosis de Ovidio}

El tema central de este trabajo es el análisis de la alimentación en las unidades domésticas campesinas como una de las expresiones de las desigualdades sociales, para ello se va a partir del análisis de las Metamorfosis de Ovidio. Aquí se ofrecen diversos mitos relacionados con actos de comensalidad. De ellos queremos destacar el episodio de Baucis y Filemón, ya que éste es uno de los pasajes donde se puede observar mejor al campesinado dentro de la obra de Ovidio.

Para introducir este trabajo, además, es necesario explicar qué entendemos por "unidad doméstica" y por qué nos centramos en el "campesinado". Preferimos usar en el análisis de la sociedad romana la expresión "unidad doméstica", y no la de familia, porque se trata de un grupo donde podemos observar tanto relaciones de consanguinidad (abuelo, abuela, padre, madre, hijo, hija), de afinidad (pareja hombre/ mujer), como de imposición (esclavo o esclava), por lo que estas relaciones pudieron ser de tipo familiar o no. Tradicionalmente estas unidades han sido presentadas por la historiografía moderna como familias, en su mayor parte sin valorar la presencia de las diversas relaciones que hubo en su seno, que, incluso, conllevaron la explotación y la dominación de unos miembros sobre otros, lo que se realizaba a través de la convivencia cotidiana. Por consiguiente, es un error considerar que dentro de estas unidades todos los individuos formaban parte de una comunidad que tenía los mismos intereses y donde los beneficios se repartían por igual. ${ }^{3}$

Por otro lado, el interés por analizar el campesinado se debe a que a lo largo y ancho del Imperio estas unidades, integradas por personas libres, constituían el grueso de los trabajadores agrícolas, es decir, la plebe rural. Éstos poseían, fueran o no de su propiedad, los medios de producción agrícola, por lo que constituían la mayoría de la población en el Imperio romano durante época altoimperial. En este sentido, hay que tener en cuenta que, aunque la forma esclavista estaba plenamente desarrollada, el sistema de villa no era dominante en todo el Estado, aunque sí determinante. En las unidades domésticas campesinas se realizaban todas las actividades productivas de la explotación agraria (tanto dentro como fuera de la casa), aunque en algunas ocasiones podían hacer uso limitado de esclavos o de trabajadores asalariados. Generalmente estaban relacionadas con una producción diversificada, es decir, un policultivo que estaba destinado principalmente para el propio consumo, así como para el pago de impuestos y rentas, y sólo una pequeña parte se destinaba a un mercado de carácter local. ${ }^{4}$ Las condiciones en las que ocupaban la tierra que cultivaban podían ser muy variadas, pues el término campesino puede incluir desde pequeños propietarios hasta coloni,${ }^{5}$ o sea, personas que trabajaban un lote de tierra que no era de su propiedad, sino que la alquilaban ya fuese mediante el sistema del arrendamiento o de la aparcería. ${ }^{6}$

\footnotetext{
Frau Llinares 1998, 17-19; Narotzky 2004, 168-171. Se ha tratado el concepto de unidad doméstica en el ámbito rural en: López Medina 2008, 199-250, donde también se aborda el debate historiográfico mencionado.

Sobre la importancia de la producción diversificada: Kolendo 1991, 247; Vera 1995, 341.

Colum. 1.7.6.

En general sobre el campesinado: Hindess - Hirst 1977, 102; Hopkins 1981, 29-30; Utchenko 1987, 43; Ste. Croix 1988, 249-250; Veyne 1992, 63; Capogrossi Colognesi 1997, 27-46; Garnsey 1998, 91-106, esp. 91. Sobre los coloni: Neeve 1984, 126-131, 141; Kolendo 1991, 247-248; Rosafio 1993, 68; Carlsen 1997, 47-60, y 2013, 75-83; Kehoe 1997, 61-73; Capogrossi Colognesi 2012, 146-155.
} 
En esta ocasión se ha elegido analizar la dieta porque es parte de la cultura alimentaria de una determinada formación social, así se desarrollan determinados hábitos alimenticios que en algunas ocasiones pueden ser expresión de las desigualdades sociales. ${ }^{7}$ En este sentido, se puede observar cómo los autores clásicos de época romana utilizaban la alimentación para contraponer lo que ellos consideraban "civilización" frente a "barbarie", con ejemplos como el consumo del vino versus la cerveza o el del aceite frente a la manteca. ${ }^{8}$ Por lo tanto, varían los productos consumidos, la forma de procesarlos y de ingerirlos, el lugar donde se toman, los rituales que los envuelven, las horas de comer, con quién se hace, etc. Además, algunos de estos productos se relacionan incluso con la religión, pues hay elementos que tienen una consideración sagrada o están asociados a determinados rituales, incluso algunos están prohibidos por la misma. Una parte de estos aspectos se irá desarrollando en este trabajo en relación con las unidades domésticas campesinas.

Bajo estos parámetros se ha escogido, para realizar este análisis, partir de la obra de Ovidio, y más concretamente de una de su madurez, sus Metamorfosis, uno de los compendios de mitología más completos que han llegado hasta nosotros. ${ }^{9}$ Esta obra se caracteriza, por tanto, por su contemporaneidad en relación con los cambios que se estaban produciendo entre finales de la República y los primeros años del Principado, ya sea en temas como la religión o la política. ${ }^{10}$ Por consiguiente, se considera una expresión de su propio tiempo, donde el mito se puede entender como una justificación del orden social establecido y a la vez sirve para su mantenimiento y reproducción. ${ }^{11}$

Como ya se ha indicado, el pasaje de Baucis y Filemón es uno de los más notorios de las Metamorfosis de Ovidio en relación a las clases sociales más desfavorecidas del mundo romano. ${ }^{12}$ En el episodio esta pareja de ancianos ofrece a Júpiter y a su hijo Mercurio alojamiento y comida después de que éstos hayan sido rechazados por los habitantes de la región de Lidia. ${ }^{13}$ Estas divinidades se presentan como huéspedes

Sobre la diversidad a la hora de la comida (alimentación, hábitos, etc.): Harris 2009, 11-17; Flandrin - Montanari 2011, 10-16.

8 Así se puede advertir en César (Gal. 6.22.1), Estrabón (3.3.7), Plinio (HN 11.239, 22.164, 28.133), Tácito (Germ. 23), por poner sólo algunos ejemplos muy conocidos y destacados.

9 Para la traducción en español hemos utilizado la edición bilingüe de las Metamorfosis de Ovidio de Ruiz de Elvira publicada por el CSIC (Madrid, vol. I-20025 , vol. II-19945, vol. III-19944), a partir de la cual se han reproducido los textos latinos, así como la edición de Álvarez - Iglesias hecha para Cátedra (Madrid, 1999³). Sobre la obra en general de Ovidio se pueden consultar los siguientes compendios: Boyd 2002; Hardie 2002. Sobre el tratamiento y su adaptación a la realidad: Hamilton 1976, 14-17; Graf 2002, 108-110. Somos conscientes de que ésta no es la única obra referida al Imperio para analizar estos aspectos, pero sí se trata de un ejemplar punto de partida para profundizar en las unidades domésticas campesinas. Entre las obras con relevantes datos sobre el campesinado podemos destacar: Moretum (el poema pseudovirgiliano) y Dafnis y Cloe de Longo.

10 En relación con su contemporaneidad: Hardie 2002, 34-44.

11 Cf. Hamilton 1976, 14-17. Para profundizar en el significado y diferentes interpretaciones de los mitos en su versión clásica y su relación con el orden social establecido: Bermejo 1979, 23-76; 1988 y 1998 ; Eliade 1991; Segal 1999; Csapo 2005. Estos aspectos se han tratado en: López Medina 2009-2010, 104-106. Sobre la importancia de esta obra para el conocimiento de la mitología griega y romana: Graf 2002, 108.

2 Ov. Met. 8.624-724.

13 En este caso se observa cómo la comunidad ha incurrido en un acto de impiedad al rechazarlos, acto que los propios dioses castigan, pues en la religión romana es a ellos a quienes les corresponde la venganza por las ofensas recibidas (Scheid 1991, 19-20). Sólo se librarán de dicha venganza la pareja formada por Baucis y Filemón, al ser los únicos que los reciben. Los acogen pese a la modestia de su residencia, una cabaña o choza -casa-(Ov. Met. 8.633, 8.699). Se trata de un alojamiento modesto en el campo, una construcción de pequeñas dimensiones (Ov. Met. 8.630), lo que, incluso, se observa cuando Júpiter y Mercurio tienen que entrar inclinados 
en un claro ejemplo de teoxenía, es decir, la epifanía de un dios bajo la figura de huésped, que es un tema recurrente en Ovidio. ${ }^{14}$ A partir de aquí se inicia la colación; en ella, y al comprobar que el vino de la crátera se reponía sin su intervención, los ancianos se dan cuenta de a quiénes han recibido, y les piden perdón por los alimentos modestos. En ese momento deciden sacrificar el único animal que poseen, en concreto, un ganso (anser), que finalmente es indultado por los dioses. ${ }^{15} \mathrm{En}$ relación con este mito, hay que destacar que es original tanto en su concepción como en su desarrollo en Ovidio y ocupa prácticamente un lugar central en su obra, lo que es indicativo de la relevancia que debió de tener para este autor; ${ }^{16}$ además, llama la atención por su relación con las unidades domésticas campesinas, y por ensalzar las virtudes de la humildad y la piedad. ${ }^{17}$

En este sentido, es interesante comparar algunos de los mitos expuestos en las Metamorfosis con el de Baucis y Filemón para determinar qué tipo de dieta se puede relacionar con las unidades domésticas campesinas y cómo ésta sirve para reproducir las desigualdades sociales existentes. Entre ellos hay que destacar el banquete de la boda de Perseo y Andrómeda y el que ofrece Anio a Eneas y sus compañeros. ${ }^{18}$ Estos dos banquetes privados los hemos resaltado por los datos que aportan para llevar a cabo la comparación, aunque también tengamos presentes otros pasajes que se describen en las Metamorfosis, y a los que se hará alusión en el desarrollo de los siguientes apartados. En el primero de ellos, el de Perseo y Andrómeda, se puede observar el sacrificio de animales asociados a este rito (concretamente la vaca -vacca-sacrificada a Minerva, el becerro -vitulus- a Mercurio y el toro-taurusa Júpiter). Se trata de un ritual dentro de la esfera privada y que al principio del libro quinto se convierte en desorden; éste se celebra en la casa de la novia, pues el anfitrión que lo organiza es su padre. En el segundo, Anio, sacerdote de Apolo,

por la exigua puerta (Ov. Met. 8.638); están construidas con materiales pobres (Ov. Met. 8.630), con un número reducido de dependencias, por lo que se caracterizan poco funcionalmente; y además presentan un mobiliario escaso, de hecho, lo que ofrecen a los dioses es su asiento (Ov. Met. 8.639-640) y un simple camastro (Ov. Met. 8.655-660). Sobre este tipo de vivienda: Mangas et alii 2013-2014, 271-298; Molina Vidal 2013, 127-140.

14 Ejemplos de ello en sus obras son la visita de Júpiter a Licaón (Ov. Met. 1.163-243), la de Ceres a la casa de Céleo y Metanira (Ov. Fast. 4.507-564) o la de Júpiter, Mercurio y Neptuno cuando visitan a Hirieo (Ov. Fast. 5.493-544).

15 Ov. Met. 8.684-688. Como ya se ha expuesto, una vez realizado el "banquete" son recompensados por su hospitalidad y generosidad, y se libran del castigo que los dioses imponen a toda la región por la impiedad anteriormente mencionada (Ov. Met. 8.689-696). Además, son premiados al ser elegidos como sacerdotes del templo en el que estos dioses transforman su modesta casa (Ov. Met. 8.697-712). Por último, al final de sus vidas son metamorfoseados en árboles (Ov. Met. 8.712-720), en concreto la encina (quercus) y el tilo (tillia) que Lélex vio en las colinas de Frigia (Ov. Met. 8.620-621); se trata de dos troncos que salen de un doble cuerpo y que son considerados sagrados, pues los habitantes de Bitinia les ponen guirnaldas, en señal de culto, de la misma forma que por imitación también hace Lélex al terminar su narración (Ov. Met. 8.721-724). Esta práctica era usual en los santuarios rurales del mundo romano, donde los altares podían estar construidos sobre piedras o peñas y los árboles allí sitos eran adornados con cintas y exvotos colgando (Blech 1999, 146-147). Un análisis sobre los distintos estudios y enfoques de este episodio y la importancia de su metamorfosis en árboles: Gowers 2005, 331-365.

16 Sobre este aspecto: Álvarez - Iglesias 1993, 20, y 1999, 499 y n. 1005; Álvarez 1999, 118 y n. 1.

17 De hecho, ella es presentada como una mujer piadosa (Ov. Met. 8.631).

18 Perseo y Andrómeda: Ov. Met. 4.735-5.235; Anio a Eneas y sus compañeros: Ov. Met. 13.632-675. Se documentan otros que no son objeto de este trabajo, pues se apartan del motivo central, y que sólo mencionamos, como son las comidas entre divinidades (entre Júpiter y Juno [Ov. Met. 3.318-321]), los actos de antropofagia (como el banquete de Licaón [Ov. Met. 1.163-243], el pasaje de Tántalo y Pélope [Ov. Met. 6.403-411]) o el canibalismo (el banquete de Tereo [Ov. Met. 6.636-674]). 
ofrece a Eneas y a sus compañeros un banquete, donde se sacrifica un buey a esta divinidad, lo que sirve para introducir la narración del secuestro de sus hijas. Este último se puede inscribir en los actos de comensalidad que se ofrecen a viajeros que hacen paradas en sus desplazamientos.

Los banquetes estudiados se pueden incluir dentro de la categoría privada, tal y como se ha adelantado. En este sentido, en el mundo romano podemos distinguir entre banquetes privados y públicos, aunque todos suelen tener un nexo religioso, pues incluso en los privados son fundamentales ciertos rituales como es el del sacrificio, a los que se ha hecho alusión, aunque en el caso del ganso, éste sea indultado por las propias divinidades, lo que hace que este episodio se sitúe más allá de una ingesta cotidiana. ${ }^{19}$ Por consiguiente, éstos tienen una gran importancia como acto social y político, y por ende religioso, puesto que no podemos olvidar que en Roma religión y política van unidos, y son contemplados como actos comunitarios, un aspecto esencial de las relaciones sociales, especialmente utilizado por las élites en Roma como instrumento de propaganda política y de formación de grupos clientelares. ${ }^{20}$

Así pues, los episodios que aquí analizamos nos pueden servir para aproximarnos a las condiciones de vida y alimentación de las unidades domésticas campesinas. Y es el análisis de todo ello lo que nos permitirá abarcar las desigualdades según la clase social en este periodo de inicios del Principado y que se pueden hacer extensivas al resto de la época altoimperial.

\section{Los alimentos en las Metamorfosis y las unidades domésticas campesinas}

Se debe empezar este apartado llamando la atención sobre varios aspectos de la dieta a tener en cuenta en el análisis. Como ya se ha expuesto, se ha considerado la colación de Baucis y Filemón como un banquete, pues cuando ambos personajes se percatan de a quiénes están recibiendo intentan sacrificar un ganso, si bien son dispensados de ello; así pues, debemos estimar que les ofrecen los alimentos de mayor calidad que tienen, por lo que no están representados todos los productos consumidos en la práctica cotidiana. De hecho, no se menciona el pan (realizado tanto con harina de cebada como de trigo), aunque sabemos que era el producto fundamental de la dieta en el mundo romano.

Asimismo, hay que tener en cuenta que la comida no significa siempre diferencias entre ricos y pobres, pues la base de la alimentación en la sociedad romana era común, consistía en cereales, de la misma forma que lo era la manera de procesarlos y cocinarlos. ${ }^{21}$ Pese a ello, éstos prácticamente no están mencionados en esta obra en relación con la nutrición, ${ }^{22}$ quizás porque no era necesario resaltarlos, ya que al ser la base alimenticia no eran una expresión de las desigualdades sociales. Esto mismo ocurre con las legumbres, como las habas o los altramuces, que eran consideradas

19 En cuanto a los banquetes públicos y privados y el carácter ritual de éstos, así como el papel que juega la carne: Van Andringa 2007; Scheid 2007. En general sobre el ritual del sacrificio con una abundante bibliografía: Alvar 2011, 21-32.

20 Cf. Dunbabin 2003, 11-13; Montero 2004, 50.

21 Cf. Wilkins - Hill 2006, 39, 52, 114-133; Corbier 2011, 254-255.

22 Ovidio hace mención a los dones de Ceres en el libro decimotercero (Ov. Met. 13.639). La importancia de los cereales en la dieta de las unidades domésticas campesinas se observa en: Moretum, 16-29, 38-50, 117. 
como parte de la comida frugal de los campesinos, de los gladiadores y, en general, como un alimento de las clases más pobres. ${ }^{23}$

Así pues, en términos generales, las unidades domésticas campesinas pudieron tener acceso a un régimen basado en la ingesta de cereales (en forma de gachas, papillas y pan), que se podían hacer más sabrosas condimentándolas, por ejemplo, con las hierbas aromáticas que podían encontrar en los alrededores o cultivar en sus huertos. Todo ello se complementaría con suplementos de proteínas, los pulmentaria, a través del acceso a la leche fresca, que les permitiría procesarla en queso para su mantenimiento, y ocasionalmente la ingesta de pescado y carne (tanto doméstica como de caza), por lo que éstos no constituyeron un alimento básico regular. ${ }^{24}$ Esto mismo se puede aplicar a los grupos desfavorecidos socialmente, como la plebe urbana; de hecho, para muchas autoridades de las civitates del Imperio, una de sus principales preocupaciones fue la de conseguir un buen abastecimiento de grano, lo que es bien conocido en el caso de Roma.

Pero, veamos qué sucede si comparamos los alimentos de Baucis y Filemón y los que aparecen en los banquetes anteriormente mencionados (Andrómeda y Perseo, y el de Anio), así como los que se documentan en otros fragmentos. Empezaremos por el consumo de proteínas. En cuanto a la ingesta de carne, en primer lugar, vamos a tratar el ganado. El principal animal que se asocia a la dieta general, y en particular a la de los más desfavorecidos, es el cerdo (sus). Se trataba de la carne más consumida, tanto por los ricos como por los pobres, sólo variaba la frecuencia en su ingesta, la complejidad de algunas recetas, la parte del cerdo tomada o la edad del animal. ${ }^{25}$ Por ejemplo, adquirir y comer ejemplares jóvenes, como el cochinillo, era considerado un lujo. Por lo tanto, el cerdo se criaba especialmente para el consumo de su carne, entre otras cuestiones porque su reproducción es rápida y se aprovecha prácticamente todo, ya que incluso algunas partes se pueden secar, por lo que se conservan durante largo tiempo. En el pasaje analizado se menciona su lomo ahumado en pequeñas cantidades, lomo que Baucis descuelga de la viga de su casa con una horquilla o furca y que ablanda con agua hirviendo. ${ }^{26}$ Según $\mathrm{M}^{\mathrm{a}}$ Consuelo Álvarez, esta parte quizás se podía referir mejor a un lomo de tocino ahumado o pinguia larda (tocino grasiento), que era la comida característica de los romanos humildes y que degustaban especialmente en las carnaria, es decir, las fiestas a la diosa Carna. ${ }^{27}$ Aparece también en otros autores de finales de la República y el Principado, como en Horacio ${ }^{28}$ Es importante destacar que asociado a él se documenta un método de conservación, como es el ahumado, lo que está en consonancia con el sacrificio de estos animales a finales del otoño y su mantenimiento, constituyendo una provisión de proteínas especialmente durante el invierno en el mundo antiguo..$^{29}$ Pero, además,

Sobre las habas: Hor. Sat. 2.3.182 y 2.6.63-64; Ov. Fast. 6.169; Plin. HN 18.101; Mart. 10.48.16. En cuanto a los altramuces: Hor. Sat. 2.3.182; Mart. 5.78.21; Colum. 2.10.1. Las propiedades nutricionales de estos últimos eran valoradas en la Antigüedad tanto por griegos como por romanos (Ov. Fast. 6.169-182; Dsc. 2.127; Macr. Sat. 1.12.33). En relación con las legumbres y su consumo por las clases más pobres: Dubois-Pelerin 2008, 65-66. Sobre la consideración de las propiedades nutricionales de éstas en el mundo clásico: Garnsey 1998, 218.

24 En cuanto a los pulmentaria: Wilkins - Hill 2006, 114; Corbier 2011, 255-256. Sobre la ingesta de pescado y carne: Wilkins - Hill 2006, 39.

25 Cf. Wilkins - Hill 2006, 144; Dubois-Pelerin 2008, 67.

26 Ov. Met. 8.648-650.

27 Ov. Fast. 6.169. Álvarez 1999, 126.

28 Hor. Sat. 2.2.117 y 2.6.64.

29 Dalby 2003, 269. 
en el caso de Baucis y Filemón se puede apreciar que su ingesta está asociada a un día especial, uno en el que tienen huéspedes; en este sentido, sabemos que la carne en general entre la plebe era consumida los días festivos.

Sin embargo, este animal no forma parte de los otros actos de comensalidad que estamos viendo. La carne tomada por los miembros de la élite está vinculada a otros productos, como los bóvidos, que están asociados a banquetes rituales, como vemos en el de celebración del matrimonio o en el de Anio. ${ }^{30}$ En cuanto al primero, el toro (taurus), la vaca (vacca) y el becerro (vitulus) forman parte de los sacrificios que se realizan a las tres divinidades asociadas a este contrato matrimonial, Júpiter, Minerva y Mercurio, ${ }^{31}$ y que el padre de la novia ofrece para la celebración que le corresponde realizar. Por lo tanto, estos animales son utilizados por un miembro de la élite como un signo de distinción social. En el segundo caso, el buey (bos) es el que se sacrifica a Apolo. ${ }^{32}$ En ambos los animales sacrificados son victimae, es decir, grandes especímenes domésticos, que convierten el acto de comensalidad en un banquete sagrado mediante el cual se permitía la comunicación entre los mortales y las divinidades. En este sentido, mediante el rito se convertía el alimento natural en divino, y obviamente eran consumidos por los que se consideraban elegidos por los dioses, en estos casos los miembros de la élite que acuden a ambos actos. El sacrificio de estos animales refuerza la cohesión de la unidad doméstica, pero también del grupo social que asiste al convivium, que en ambos casos es un acto privado, pues a ellos estarían invitadas personas que pertenecían a la misma condición social o los clientes y que, por tanto, mantenían relaciones de amicitia y clientelismo con el paterfamilias, lo que sin duda alguna se utilizaba para justificar y mantener el orden social.

Así pues, pese a que la mayor parte del ganado vacuno se usaba como animal de trabajo en el campo y para la tracción de vehículos, y las hembras también se valoraban por su leche y la reproducción, una parte de ellos, especialmente del buey, estaba destinado al sacrificio, por lo que era uno de los animales más preciados para estos fines al asociarlo a numerosos rituales. ${ }^{33} \mathrm{Su}$ adquisición requería grandes dispendios por lo que se debe vincular al uso prácticamente exclusivo de la élite, como ocurre en la obra analizada, y su sacrificio está relacionado con actos muy solemnes, como es el caso del matrimonio, lo que demuestra una gran piedad, a la par que una exhibición de la posición económica y social del paterfamilias, pues obviamente todos los contratos matrimoniales no podían ser ratificados de la misma forma.

También asociado a la comida de la élite está el consumo del cordero (agnus). ${ }^{34} \mathrm{Su}$ carne era muy apreciada, siendo un animal común en los sacrificios. ${ }^{35} \mathrm{Su}$ importancia también se puede poner en relación con la producción de leche (lac) y unido a ello su uso para hacer queso. ${ }^{36} \mathrm{Si}$ se tiene en cuenta que la leche es un producto perecedero que se descompone con suma rapidez, su conservación debió de ser un gran problema en la Antigüedad, por lo que, según Andrew Dalby, su consumo como leche fresca

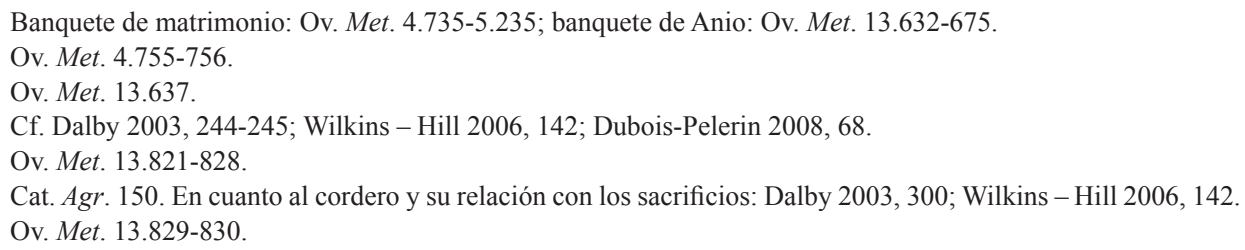


estaría relacionado directamente con granjeros y pastores, es decir, con el ámbito rural, mientras que en las ciudades debía ser un producto muy caro, por lo que su ingesta debió de ser limitada. ${ }^{37}$ En consecuencia, una parte importante de la leche estaba reservada para fabricar queso, lo que permitía una aportación de proteínas y calcio de manera regular al mantener mediante esta forma de conservación gran parte de sus nutrientes. Así, el queso está presente entre los alimentos de Baucis y Filemón, ${ }^{38}$ en consonancia con su condición de producto consumido habitualmente en el mundo romano. Esto está constatado tanto en el registro arqueológico (se documentan objetos para su fabricación desde la Prehistoria), como a través de las fuentes literarias. ${ }^{39}$ Además, hay que destacar que el queso a menudo era degustado con miel, especialmente el fresco, ${ }^{40}$ lo que está en relación con la presencia de un panal de miel en este mismo pasaje. ${ }^{41}$

Por otro lado, es de interés analizar el consumo de las aves. En concreto, en el mismo episodio, se señala al ganso (anser), mientras que en otras partes se mencionan aves de manera genérica, haciendo alusión específica a la paloma (columba) ${ }^{42}$ Ésta era valorada como una fuente de comida fina. ${ }^{43}$ En cuanto al ganso, es mencionado entre las aves que crían los campesinos; de hecho, Ovidio en esta obra escribe que es el guardián de la pequeña granja, y autores como Columela expresan que era consumido especialmente por ellos. ${ }^{44}$ Se consideraba sagrado entre otras razones porque se creía que era el animal favorito de Juno y protector de Roma, ya que cuando la ciudad fue asediada por los galos en el 390 a.C. y escalaron de noche el Capitolio, éste dio la voz de alarma; ${ }^{45}$ asimismo, estaba vinculado a Príapo y a la fecundidad. Esta apreciación provocó que su ingesta no fuera bien vista en los banquetes, sin embargo, ya en época de Augusto formaba parte de los alimentos en los convivia, siendo especialmente valorado por su carne, sus huevos y su paté. ${ }^{46}$ Como ya se ha expuesto, Baucis y Filemón, al advertir que el vino no se terminaba, se dieron cuenta de que habían recibido en su humilde casa a dioses e intentaron sacrificarlo. En este caso la ofrenda que se pretendía realizar era la de un animal menor o de pequeño tamaño, por lo que estaríamos ante una hostia si el sacrificio se hubiera producido, y el animal no hubiera sido indultado por las divinidades.

Con respecto al resto de las aves, tampoco se podían consumir una larga lista de ellas, posiblemente las silvestres, de la misma forma que ocurría con el buey en los orígenes de Roma; esto era debido a las virtudes que se les conferían y a que se consideraban animales cercanos a los dioses, tal y como analiza Santiago Montero. ${ }^{47}$ Esta prohibición, unida a un cierto temor, desapareció gradualmente a lo largo del siglo II a.C., aunque durante ese siglo se seguía legislando contra la ingesta

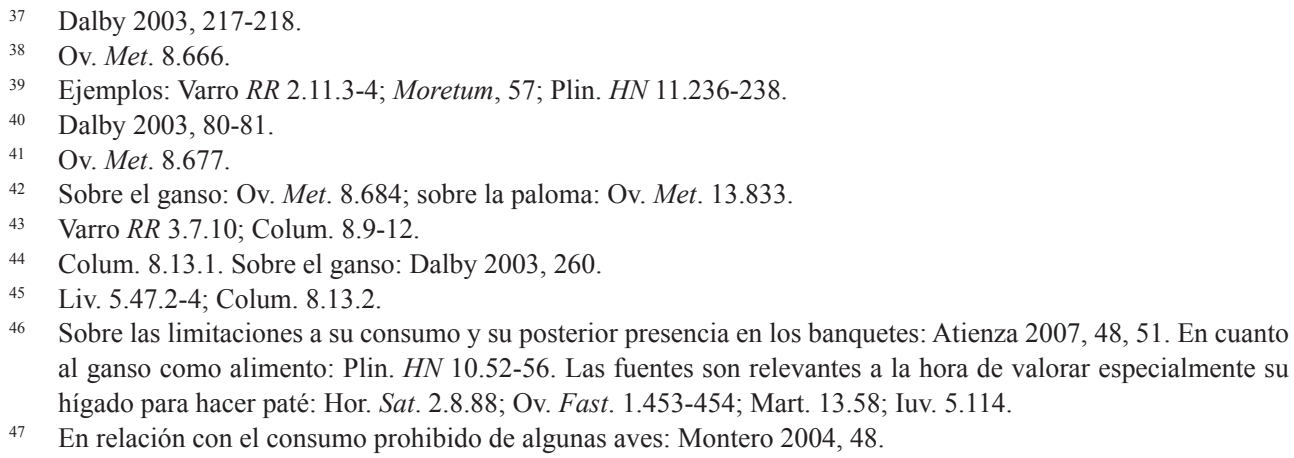


especialmente de aves raras o exóticas. ${ }^{48}$ Así pues, éstas pasaron a formar parte de los banquetes en general, como, por ejemplo, se aprecia en Horacio, quien menciona el consumo de gallinas y otra serie de aves raras como el pavo real, la cigüeña o el urogallo ${ }^{49}$. En este sentido, hay que resaltar que tuvieron un papel muy importante en la dieta antigua, pues su ingesta proporcionaba proteínas de manera barata a gran parte de la población. ${ }^{50}$ Incluso su consumo se asoció con la medicina y la salud; por ejemplo, Celso recomendaba tomar determinados tipos de aves para según qué enfermedades. ${ }^{51}$ En las Metamorfosis también se puede observar esta relación, cuando el enfermo y hambriento Filoctetes se alimenta de éstas. ${ }^{52}$

Pero, además, se ha visto que dentro de los productos que ofrecen Baucis y Filemón aparecen los huevos (ova). ${ }^{53}$ Generalmente los consumidores producirían sus propios huevos a partir de las aves de corral, especialmente de las gallinas, que debieron de ser los más ingeridos, puesto que los de otras especies estaban relacionados con el lujo en la colación. Su única mención en esta obra es en relación con la dieta de la plebe, pero se sabe que en los convivia no podían faltar los huevos durante la gustatio, es decir, al inicio de éstos, donde se ofrecían una serie de entremeses cuya misión era la de estimular el apetito. ${ }^{54}$

Por último, no debemos dejar de mencionar la carne de los animales de caza. En las Metamorfosis se hace alusión al gamo (dama), el macho cabrío (caper) y la liebre (lepus)..$^{55}$ El consumo de este tipo de producto cárnico se constata principalmente a través de los restos óseos de los yacimientos arqueológicos, especialmente en contextos de habitación y, por tanto, vinculados a la alimentación, por lo que debió de ser una aportación común de proteínas, un complemento de la dieta alimenticia de todos los grupos sociales. Dentro de ellos hay que hacer una mención especial a la liebre. En Roma, era recomendada por los médicos y su consumo era abundante, como prueba el hecho de que fueran tanto cazadas como criadas en las granjas, en concreto, en unos recintos denominados leporaria. ${ }^{56}$

Por consiguiente, vemos cómo en esta obra la ingesta de productos cárnicos, o derivados de ellos, era una expresión de la desigualdad social. Esto es especialmente significativo en relación con el cerdo frente a los bóvidos. Por ello el consumo de determinados tipos de productos cárnicos está asociado a una elevada posición social. Aquí la mayor capacidad adquisitiva de la élite les permitiría conseguir a los últimos (bueyes, vacas...), por lo que, además, se convierten en un indicador de sofisticación, riqueza y poder, es decir, de status social, como han destacado John M. Wilkins, Shaun Hill o John Scheid. ${ }^{57}$

Por otro lado, llama la atención que en la obra no aparezca en ningún momento el consumo de pescado. Su ausencia quizás se deba relacionar con la idea de que nunca

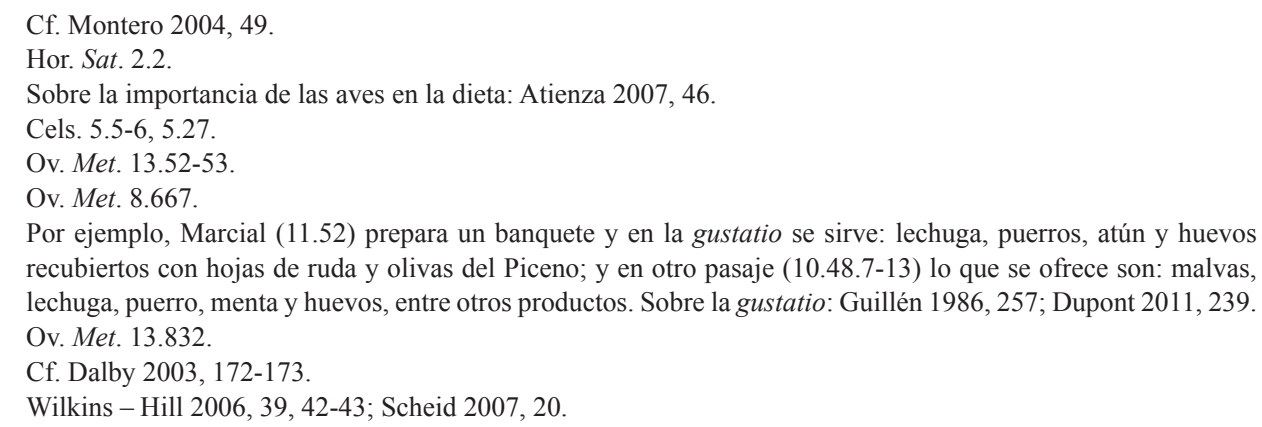


pudo ser sacrificado, pues no era un animal doméstico. ${ }^{58}$ Sin embargo, sí fue un producto ingerido en el mundo grecorromano como demuestran, por ejemplo, la comedia griega o las representaciones de las pinturas pompeyanas. De hecho, durante el periodo clásico muchas especies de pescado fueron capturadas y consumidas y se hicieron derivados como las salazones o las salsas, entre las que destacan el garum o la liquamina, incluso se construyeron criaderos de pescado en Italia a partir del periodo tardorrepublicano. ${ }^{59}$ En este sentido, los análisis de isótopos estables realizados a individuos de Herculano y de Velia, poblaciones costeras de Italia, confirman que los recursos marinos fueron una de las fuentes de alimentación en las dietas de estas comunidades. ${ }^{60}$ Además, algunas especies, incluyendo crustáceos, se consideraban un manjar en los convivia de la élite y llegaban a alcanzar precios astronómicos, sobre todo si eran de importación. ${ }^{61}$

En relación con los productos agrícolas, éstos son mostrados como la base de la dieta tanto en el banquete de Baucis y Filemón como en los otros, especialmente en el de Anio, ${ }^{62}$ si bien aquí se observa que principalmente formaban parte del acompañamiento de los productos cárnicos. Así pues, en las Metamorfosis aparecen vinculados a la alimentación de todos los grupos sociales, lo que nos indica la importancia que tuvo la agricultura como base económica. De hecho, la relevancia de los productos agrícolas es resaltada al poner en boca de Anio que todo lo que tocaban sus hijas se convertía en cosecha, en vino y aceite. ${ }^{63}$

En cuanto a las verduras, se mencionan en el pasaje de Baucis y Filemón como producidas en su regado huerto,${ }^{64}$ lo que alude a la importancia de la autosuficiencia, y donde Ovidio destaca en general la verdura (olus), pues hace mención a hojas puestas a cocer, y en particular a la endivia (intibum) y el rábano (radix) ${ }^{65}$ Con respecto a las frutas, tanto frescas como secas, se hace alusión a ellas entre los alimentos de la plebe y en los de la élite, siendo comunes a ambos el consumo especialmente de las uvas (uvae). ${ }^{66}$ Además, se mencionan las fresas (fraga), las cerezas silvestres o frutos del cornejo (corni), las ciruelas (pruna), las manzanas (mali), las aceitunas o frutos bicolores de Minerva (olivae) -que debían ser sometidas a un proceso de curación, ya que al natural están amargas, y que solían ser consumidas en la gustatio junto a los huevos duros-, las castañas (castanae), las nueces (nucis), el fruto del madroño (arbutei fetus), los higos secos (caricae) - este método de conservación permitía que se mantuvieran todo el año y al ser dulces suponían un buen aporte de azúcar a

\footnotetext{
Cf. Detienne 1979, 10; Wilkins - Hill 2006, 142.

Varro RR 3.3.2, 3.3.4, 3.17; Colum. 8.16-17.

Craig et alii 2013, 350-351.

Dubois-Pelerin 2008, 71.

Banquete de Baucis y Filemón: Ov. Met. 8.645-647, 8.664-669, 8.674-676; banquete de Anio: Ov. Met. 13.639. Ov. Met. 13.652-654.

La relevancia del huerto en las pequeñas propiedades o explotaciones también se observa en: Moretum 60-76.

Sobre la verdura: Ov. Met. 8.645-646; sobre la endivia y el rábano: Ov. Met. 8.666. Las endivias se pueden comparar con la lechuga (lactuca), aunque la primera a menudo era cocinada antes de servirla para reducir su amargor; la lechuga también formaba parte de la alimentación popular (Moretum 74; Apul. Met. 9.32.4), aunque era apreciada en todo el Imperio. La importancia de la ingesta de esta última se observa en Marcial (3.50.4, 5.78.4, 10.48.9, 11.52.5, 12.19, 13.14). Cf. Dubois-Pelerin 2008, 66 y n. 39. Con respecto a los rábanos, en Roma durante el periodo imperial se distinguen dos variedades, la más antigua y familiar, la negra, y un nuevo tipo más pequeño y rojo (Varro $L L$ 5.21.3; Varro RR 1.24.1, 3.16.25; Hor. Sat. 2.8.8-9; Colum. 9.4.5; Plin. HN 15.30, 19.75-87, 20.22-28, 20.96; Dsc. 2.112).

${ }_{66}$ En relación con la fruta: Ov. Met. 8.664-666, 8.674-676, 13.812-820; sobre las uvas: Ov. Met. 8.676, 13.813814.
} 
lo largo del mismo-y los dátiles (palmae). ${ }^{67}$ Estos últimos, también ricos en esta sustancia, fueron un manjar popular en Roma ${ }^{68}$

Otro de los productos mencionados es la miel. En esta obra es el elemento esencial de los manjares asociados a las divinidades, como es el caso del néctar, ${ }^{69}$ pero también se consume entre los personajes con características humanas, de hecho, en el episodio de Baucis y Filemón se alude a un panal, ${ }^{70}$ lo que hemos vinculado anteriormente con el queso fresco. Su relevancia radica en que este producto era el principal edulcorante de la Antigüedad, ${ }^{71}$ lo que justifica, por ejemplo, que en la literatura clásica Virgilio dedicara en sus Geórgicas el libro cuarto a la apicultura. Así pues, la miel se ofrecía en los rituales a los dioses y era un producto común en los banquetes, de ahí posiblemente que Ovidio destaque la presencia de un panal y su miel en el pasaje mencionado.

Por último, nos queda mencionar la bebida por excelencia de la Antigüedad clásica, el vino, del que existen diversas variedades. En este caso podemos observar que era básico tanto en los banquetes de la élite como en los de la plebe, de hecho, en el de Baucis y Filemón "milagrosamente" nunca se terminaba. ${ }^{72}$ No obstante, existe una gran diferencia, el ofrecido por éstos presentaba una calidad claramente inferior al no ser añejo como demuestra la frase: nec longae rursus referuntur vina senectae ${ }^{73}$ sin embargo, los invitados a los banquetes de la boda de Andrómeda y Perseo o el de Anio beben vino de excelente calidad. ${ }^{74}$ En este sentido, se entendía por "excelente calidad" el más viejo, o sea, que había pasado al menos un año desde su producción, como expresa el jurista Ulpiano. ${ }^{75}$ El vino era una bebida tomada a diario en todas las comidas, pues no se debe olvidar que también es considerado un alimento ${ }^{76}$ incluido el consumo de uvas, y, como se desprende de lo anterior, ingerido por todas las clases sociales.

En esta obra, tal y como hemos visto, se relaciona con contextos de convivia $\mathrm{y}$, por lo tanto, está asociado principalmente a los momentos donde la palabra tomaba relevancia, de ahí que determinadas actuaciones como las conversaciones tuvieran un especial significado durante y tras los banquetes, como en el de Anio, cuando éste servía para introducir el secuestro de sus hijas, o el propio pasaje de Baucis y Filemón, que lo contaba Lélex durante el transcurso de su estancia junto a Teseo en la casa de Aqueloo. ${ }^{77}$ Por lo tanto, el vino se consideraba una herramienta

67 Fresas: Ov. Met. 13.816; cerezas silvestres o frutos del cornejo: Ov. Met. 8.665, 13.816; ciruelas: 8.675, 13.817; manzanas: Ov. Met. 8.675; aceitunas: Ov. Met. 8.664; castañas: Ov. Met. 13.819; nueces: Ov. Met. 8.674; frutos del madroño: Ov. Met. 13.820; higos secos: Ov. Met. 8.674; dátiles: Ov. Met. 8.674.

68 Sobre los dátiles: Dalby 2003, 113-114.

69 Ov. Met. 3.318, 10.160-161. Sobre el néctar, entre otros: Lazzeroni 1988, 177-199; Uría 1992, 141-145; Muñoz Llamosas 1998, 147-160.

70 Ov. Met. 8.677.

71 Chic García 1997, 59-60; Dalby 2003, 179-180; Wilkins - Hill 2006, 160-161.

72 Ov. Met. 8.679-681.

73 "Y se trae a continuación vino no muy añejo" (Ov. Met. 8.672).

74 Ov. Met. 4.765-766, 13.639.

75 Dig. 33.6.11: Vetus accipietur quod non est novum: id est anni prioris vinum appellatione veteris continebitur ("Se tiene por añejo el que no es nuevo, es decir, se contendrá en la denominación de vino añejo el del año anterior” [Ulp. 23 Sab.]). Sobre el vino añejo: Dubois-Pelerin 2008, 77.

76 Real 1992.

77 Banquete de Anio: Ov. Met. 13.640-674. Pasaje de Baucis y Filemón: Ov. Met. 8.547-724. El asociar banquete y conversaciones es un procedimiento típico de la epopeya: Álvarez-Iglesias 1993, 1-24; Álvarez 1999, 118-119. 
para abrir la mente, vencer la timidez, animar el ingenio, en definitiva, entablar conversación. ${ }^{78}$

Pero debemos tener en cuenta que la mayor parte de los organizadores de convivia pertenecerían a la élite, mientras que los integrantes de las unidades domésticas campesinas lo harían sólo en momentos excepcionales como la celebración de los rituales de matrimonio y otras festividades de carácter familiar, y, por supuesto, sin la opulencia de los primeros.

\section{Alimentación, desigualdades sociales y austeridad en las Metamorfosis}

Según lo que hemos analizado, se puede constatar a través de esta obra que había determinados productos que se pueden considerar específicos, especialmente aquellos que formaban parte de los distintos rituales y que a través del sacrificio pasaban a presentar un valor simbólico, como ocurre en los casos de la boda entre Andrómeda y Perseo, o del banquete de Anio, incluso aquí podríamos incluir al indultado ganso del episodio de Baucis y Filemón. También había alimentos especiales por causa de su escasez o por sus propiedades curativas, como se ha analizado en el caso de las aves. Frente a ellos, existían toda otra serie de productos que o bien marcaban las desigualdades de clase (como los bóvidos) o eran propios de cualquier acto de consumo diario y en el caso de los convivia sólo servían como acompañamiento (como ocurre con las verduras).

Estos últimos son los que nos permiten acercarnos a la alimentación de las unidades domésticas campesinas, que se basaba en los productos del huerto (ya sea de su propia cosecha o procedentes de otros productores, es decir, de la agricultura local, como se ve en el pasaje de Baucis y Filemón al mencionar que se alimentan de las verduras de su regado huerto). Éstos estaban compuestos principalmente por cereales, legumbres, verduras y frutas. Por tanto, las verduras formaban parte de la base de la dieta de los pobres. Una expresión de ello nos llega a través de la arqueología, en concreto nos referimos a una lucerna con la figura de Aquiles, donde además se representa una cesta con una jarra de vino, un pan y un rábano, y se puede leer la siguiente leyenda: pauperis cena $(\mathrm{m})$ : pane $(\mathrm{m})$ vinu $(\mathrm{m}) \mathrm{radic}(\mathrm{em}) .{ }^{79} \mathrm{~A}$ esto se sumaba el aporte de proteínas principalmente a través de productos como el cerdo y los huevos, si bien hay que destacar que su consumo se vinculaba especialmente con los días festivos o especiales, como se ve en el pasaje de Baucis y Filemón, pues descuelgan la pieza de cerdo porque están recibiendo invitados, concretamente a las divinidades en un ejemplo de teoxenía.

Frente a ellos las personas que pertenecían a la élite recibían un aporte de proteínas de origen animal de manera más frecuente, por lo que la ingesta de carne, entre ella la bovina, era un indicador de riqueza ${ }^{80}$ a lo que hay que sumar la de productos de lujo como las especias, el vino de calidad, las exquisitas salsas de pescado, etc. La adquisición de todos estos productos requería de un elevado poder adquisitivo, por

78 Lejavitzer 2008, 114. Se puede apreciar en autores clásicos como Horacio (Sat. 2.2, 2.8) o Aulo Gelio (13.11.13).

79 CIL III 14114,13a: "Cena de pobre: pan, vino, rábano". Sobre las verduras como base de la dieta de los pobres: Dubois-Pelerin 2008, 67; Corbier 2011, 245.

80 Wilkins - Hill 2006, 142-143; Dubois-Pelerin 2008, 65-66. 
lo que se convirtieron en un signo de status social para la élite. En este sentido, la carne, tanto de animales domésticos como de caza, era consumida principalmente por los miembros de esta clase social, mientras que los de la plebe ingerían más productos agrícolas, especialmente verduras, como observamos en la colación dada en las Metamorfosis a Júpiter y Mercurio.

Por otra parte, hay que tener en cuenta que el abanico de estas unidades domésticas campesinas era muy amplio y sus condiciones de vida muy variadas, ya que dependían del tamaño de la explotación agrícola, la fertilidad del terreno, etc. Esto significa que, aunque la dieta tuviera un núcleo común, debieron de existir diferencias en el acceso a determinados productos dependiendo de las circunstancias de cada uno, por ejemplo, de la región en la que habitaran, pues también se ha analizado que algunos productos procedían de la recolección o la caza. Así pues, los campesinos tendrían acceso a diferentes plantas aromáticas, a pájaros locales o pescado de la zona, dependiendo este último de su cercanía a los ríos o a la costa. En cuanto a las plantas silvestres o herbae en líneas generales estaban excluidas de la mesa de las personas más ricas, salvo algunas excepciones, como el champiñón o el espárrago, y las que podían servir por sus propiedades medicinales, como las ortigas. ${ }^{81}$

Por lo tanto, esta alimentación coincidiría en gran medida con la que Lin Foxhall y Hamish A. Forbes ponen de manifiesto en su trabajo sobre una comunidad de campesinos cercana a Khania en Creta (que fue analizada por Leland G. Allbaugh entre 1947-1948). ${ }^{82}$ Ésta estaba dominada por los cereales, acompañada de aceitunas, legumbres, plantas silvestres/herbae, frutas y una pequeña cantidad de carne de cabra, leche de cabra, carne de caza y pescado. Por consiguiente, pese a la ingesta de proteínas a través de los productos cárnicos y de los marinos, la mayor parte de la dieta estaba compuesta por productos agrícolas, al menos en un $50 \%$, aunque en la mayor parte de los casos se estima que ascendía al $75 \%$, como ponen de manifiesto los estudios de Lin Foxhall, Hamish A. Forbes, Peter Garnsey o los del equipo de Oliver E. Craig. ${ }^{83}$

Teniendo en cuenta el análisis de las desigualdades sociales en relación con la alimentación, no se puede terminar este estudio sin resaltar otro aspecto: el de la austeridad y la vinculación que hace Ovidio de ésta a la dieta de las unidades domésticas campesinas o de la plebe en general, ya que la considera como el prototipo de la alimentación, lo que, desde nuestro punto de vista, se realza con la posición central en su obra del episodio de Baucis y Filemón. Esto provoca que en sus Metamorfosis haga una crítica a la opulencia frente a la austeridad. Esta crítica era justificada mediante la filosofía pitagórica, lo que se observa en sus alusiones a la mítica Edad de Oro. ${ }^{84}$ En este sentido, la filosofía neopitagórica, que se desarrolló especialmente en el sur de Italia y tuvo una gran influencia en los poetas de época augustea, como es el caso que nos ocupa, basaba sus preceptos en cuanto a la alimentación en dos principios: todos los seres vivos son de la misma condición, y la creencia en la metempsicosis o reencarnación tras la muerte en un ser de forma humana, vegetal o animal. ${ }^{85}$

\footnotetext{
Mart. 3.45.3, 3.45.6; Iuv. 11.68-69, 14.8. Sobre las herbae: Dubois-Pelerin 2008, 66; Dupont 2011, 233.

Foxhall - Forbes 1982, 41-90.

Foxhall - Forbes 1982, 62-65; Garnsey 1983, 118-130; Craig et alii 2013, 350.

Ov. Met. 1.89-112, 15.96-111.

El neopitagorismo se desarrolló especialmente en el sur de Italia, y estuvo influenciado por aspectos del platonismo y el estoicismo. Cf. Gascó 1991, 195-198; Ramos 2003, 149-160. Sobre los preceptos pitagóricos de la alimentación se puede consultar entre otros: Guthrie 1984, 182-188. Sobre la metempsicosis Ovidio la
} 
Estos principios provocaron que sus seguidores practicaran una dieta austera y fueran contrarios a los banquetes y especialmente al consumo de carne. ${ }^{86}$ Aunque Ovidio hacía referencia para esta crítica a los pitagóricos, sabemos que existieron otras corrientes filosóficas que también se pronunciaron contra el consumo de carne, como los estoicos y los epicúreos, incluso estos últimos llevaron a cabo una dieta vegetariana. ${ }^{87}$ Así pues, para Pitágoras y sus seguidores el mejor sustento estaba compuesto por mieses, frutos, uvas, hierbas dulces, leche, miel, como se consideraba que había ocurrido en la Edad de Oro. De este modo, el pasado y la recolección en esta etapa como algo positivo es repetitivo en la obra de Ovidio, pues se ve también en Amores. ${ }^{88}$

Así, una alimentación exclusivamente vegetariana era un sinónimo de frugalitas, y ésta estaba atribuida normalmente a la Roma antigua, donde la puls o polenta de cereales era considerada la base de la dieta. ${ }^{89} \mathrm{El}$ mismo Ovidio comenta que era un crimen cargar la mesa de carnes, cuando se tenía un hortus que daba frutos de la tierra, así como productos lácteos y miel..$^{90}$ Se trata, por lo tanto, de una idea que provocó que el hortus se convirtiera en un tópico de época republicana e inicios del Principado al que también hacían alusión Catón o Columela. De acuerdo con esto, el huerto era fundamental para los romanos, lo contemplaban como el lugar del que se extraían los mejores productos, los olera, es decir, las hortalizas, por lo que debía estar en producción prácticamente todo el año (de hecho, incluso en las domus de las ciudades se intentaba tener uno, como demuestran las excavaciones de Pompeya y Herculano). Esto condujo a que el hortus se relacionara con la tierra cultivada que era exponente de "civilización", de la misma forma que su producción, o sea, las hortalizas junto con las frutas, representaban los alimentos que estimaban más "civilizados". ${ }^{91}$ Por lo tanto, su producción de carácter autosuficiente, que se ve en Ovidio y en los agrónomos latinos, se encontraba relacionada con otra idea: la de una alimentación basada en la austeridad.

Sin embargo, a partir del siglo II a.C. la influencia helena, y en general oriental, fue operando cambios en la dieta romana, que en origen era austera y pobre, típica

plantea en su obra de la siguiente forma: omnia mutantur, nihil interit: errat et illinc. / Huc venit, hinc illud et quos libet occupat artus / spiritu eque feris humana in corpora transit / inque feras noster, nec tempore deperit ullo, / utque novis facilis signatur cera figuris / nec manet, ut fuerat, nec formas servat easdem, / sed tamen ipsa eadem est, animam sic simper eandem / esse sed in varias doceo migrare figuras ("Todas las cosas cambian, nada muere: el espíritu vaga errante y va de allá para acá, de acá para allá y ocupa cualesquiera miembros y de los animales pasa a los cuerpos humanos y a los animales el nuestro, y no perece en ningún momento, y como la cera se marca fácilmente con nuevas figuras y no permanece como había sido ni conserva las mismas formas pero, con todo, ella es la misma, así enseño que el alma es siempre la misma pero emigra a diferentes figuras", Ov. Met. 15.165-172).

86 En relación con el debate filosófico sobre la alimentación: Wilkins - Hill 2006, 187-210.

87 Los estoicos consideraron que las relaciones entre hombres y animales eran diferentes, pues a unos les estaba reservada la ratio, mientras que a otros la natura o instinto. Pese a todo, reconocían que ciertos animales estaban al servicio del hombre y podían ser consumidos. Para los epicúreos los hombres y los animales eran de una misma naturaleza; estaban compuestos de átomos que tras la muerte se descomponen y se recomponen bajo una forma humana, animal o vegetal, de ahí que fueran partidarios de llevar a cabo una dieta vegetariana. Sobre estos aspectos: Montero 2004, 59-60.

88 Ov. Am. 3.10.5-10.

89 Val. Max. 4.3.5. Sobre la puls: Cat. Agr. 85; Varro LL 5.22.1, 5.27.2; Plin. HN 18.83-84; Iuv. 14.171. Cf. Mayer 1993, 16; Dubois-Pelerin 2008, 65; Corbier 2011, 254.

90 Ov. Met. 15.75-95.

91 Cf. Dupont 2011, 229. 
de una sociedad rural. Estas transformaciones afectaron a los convivia, que se volvieron más opulentos, como se ha puesto de relieve, lo que estaba relacionado con la expansión territorial y la apertura de las rutas comerciales. ${ }^{92}$ A este respecto, durante los siglos II-I a.C. se promulgaron las leges sumptuariae para frenar el consumo ilimitado de productos exóticos y caros en las comidas debido a lo que se consideraba como una relajación en las costumbres alimentarias,,$^{93}$ lo que era calificado por Catón como un descuido del mos maiorum por parte de los ciudadanos romanos y una corrupción de las costumbres. ${ }^{94}$ Pese a ello, estos productos llegaron a los paladares más exquisitos de la Roma imperial y terminaron apareciendo en obras como las de Petronio, Juvenal, Horacio o Marcial. Todo ello es un indicador del abandono progresivo de la posición antisuntuaria, lo que llevó a que, incluso, en el siglo I d.C. dejaran de tener efecto las leyes anteriormente mencionadas. Frente a esta posición hubo autores que siguieron recomendando el consumo austero, como Horacio, que relaciona frugalidad en la dieta con buena salud; Plinio, que llegó a decir que las clases más pobres tenían una alimentación más sana que los ricos, pues reducían su sustento a los productos del hortus; Plinio el Joven, que hacía alusión a la importancia de una comida simple basada en los productos agrícolas, junto con algunas legumbres y algo de carne; o el propio Ovidio, como se ha analizado. ${ }^{95}$ Éste llevó al extremo en las Metamorfosis la crítica a la opulencia en el comer con la escenificación de la gula representada en el pasaje de Erisicton. ${ }^{96}$

Ahora bien, debemos tener en cuenta que estas discusiones entre austeridad y opulencia incidirían solamente en la élite, porque, como hemos expresado, la mayor parte de la sociedad, donde deben ser incluidas las unidades domésticas campesinas, no tuvo la posibilidad de elegir y se vio obligada a mantener una dieta frugal, como nos ha permitido analizar el mito de Baucis y Filemón.

\section{Conclusiones}

Tal y como ya se ha expresado, los mitos son una expresión de las desigualdades sociales en los que es necesario seguir profundizando desde diversos puntos de vista para aproximarnos a la sociedad romana, no sólo para examinar cómo vive la élite, sino otros grupos sociales, como es la plebe y, en concreto, las unidades domésticas campesinas. Así pues, tras el análisis de los alimentos observamos esas diferencias en los mitos de las Metamorfosis. En este sentido, pese a que todos tenían una misma base alimenticia (los cereales), su consumo presentaba grandes disparidades según las clases sociales, como se ha visto en los apartados anteriores.

Teniendo en cuenta esto, queremos destacar cómo esta obra sirve para reafirmar la dieta austera y frugal de estas amplias comunidades, pese a las diferencias internas que había entre ellas (tanto económicas como de ubicación en un determinado territorio). Por lo tanto, ésta, y en especial el episodio de Baucis y Filemón, es

\footnotetext{
Plin. $H N$ 15.105. Cf. Santapau 2004, 7-9.

Gell. 2.24; Macr. Sat. 3.17.

94 Liv. 34.4.4. Cf. Mayer 1993, 17; Drinkwater - Drummond 1994, 140; Montero 2004, 49; Dubois-Pelerin 2008, 86-91.

95 Hor. Sat. 2.2; Ep. 1.18; Plin. HN 19.52; Plin. Ep. 1.15.2.

96 Ov. Met. 8.725-878.
} 
una fuente para analizar la alimentación de las unidades domésticas campesinas que estaría basada en el consumo de cereales, legumbres y vegetales, aunque aquí sean obviados los dos primeros, posiblemente por su universalidad, como se ha explicado anteriormente. A ello hay que sumar las herbae; de hecho, su consumo está relacionado con la pobreza y el hambre, así se puede observar en un episodio de las Metamorfosis, cuando Ovidio hace referencia a que se ve al Hambre, buscando y arrancando con uñas y dientes las hierbas. ${ }^{97}$ Por último, hay que añadir el aporte de proteínas, especialmente a partir del cerdo, los huevos, el queso o la miel, si bien hay que destacar que el consumo de algunos de estos productos, como la carne del cerdo, se vinculaba especialmente con los días festivos o especiales, como se ve en el pasaje de Baucis y Filemón. Por último, no se puede dejar de hacer alusión al vino como uno de los productos alimenticios consumidos a diario por estas unidades.

Para finalizar, a nuestro juicio, la posición central del episodio de Baucis y Filemón en la obra se puede relacionar con la legitimación y reproducción de este tipo de alimentación en el campesinado, frente a la observada en los banquetes de la élite. En este sentido, la austeridad destacada en toda la obra bien pudo ser utilizada por las clases dirigentes como un recurso para justificar este tipo de alimentación por parte de la mayor parte de la población, $y$, por lo tanto, para mantener el orden social existente a inicios del Principado, y durante el resto del Alto Imperio, que está basado en las grandes desigualdades.

\section{Referencias bibliográficas}

Alvar, J. (2011): “La alquimia del alimento: el sacrificio ritual”, ARYS 9, 21-32.

Álvarez, M. C. (1999): “Filemón y Baucis”, [en] E. Fernández de Mier - F. Piñero (eds.), Amores míticos, Madrid, 117-135.

Álvarez, M. C. - Iglesias, R. M. (1993): "Relatos de banquete en las Metamorfosis de Ovidio", [en] UA 10, Vino y banquete en la Antigüedad, Valdepeñas, 1-24.

Álvarez, M. C. - Iglesias, R. M. (1999), (eds. y trads.): Ovidio, Metamorfosis, Madrid.

Atienza, A. M. (2007): “Comedores de pan y bebedores de vino: la cuestión alimentaria en la Odisea", Circe de clásicos y modernos 11, 41-56.

Bermejo, J. C.

(1979): Introducción a la sociología del mito griego, Madrid.

(1988): El mito griego y sus interpretaciones, Madrid.

(1998): "Mitología Clásica y Antropología”, Habis 29, 335-347.

Blech, M. (1999): "Exvotos figurativos de santuarios de tradición ibérica en la época romana en la Alta Andalucía", [en] V. Salvatierra - C. Rísquez (eds.), De la sociedad agrícola a la Hispania romana, Jaén, 143-174.

Boyd, B. W. (ed.), (2002): Brill's Companion to Ovid, Leiden (https://doi. org/10.1163/9789047400950).

Capogrossi Colognesi, L.

(1997): "Lavoro agricolo e strutture fondiarie", [en] Lo Cascio (cur.), 1997, 27-46.

(2012): Padroni e contadini nell'Italia Repubblicana (=“L'Erma" di Bretschneider. Saggi di storia antica 34), Roma.

Ov. Met. 8.799-800. 


\section{Carlsen, J.}

(1997): “I sovrintendenti degli affittuari durante il Principato", [en] Lo Cascio (cur.), 1997, 47-60.

(2013): Land and Labour. Studies in Roman Social and Economic History (="L'Erma" di Bretschneider. Saggi di Storia Antica 37), Roma.

Chic García, G. (1997): "La miel y las bestias", Habis 28, 153-166.

Corbier, M. (2011): "El haba y la morena: jerarquías sociales de los alimentos romanos", [en] Flandrin -Montanari (dirs.), 2011, 245-270.

Craig, O. E. et alii (2013): "Evaluating marine diets through radiocarbon dating and stable isotope analysis of victims of the AD 79 eruption of Vesuvius", American Journal of Physical Anthropology 152/3, 345-352 (https://doi.org/10.1002/ajpa.22352).

Csapo, E. (2005): Theories of Mythology, Malden.

Dalby, A. (2003): Food in the Ancient World. From A to Z, London-New York.

Detienne, M. (1979): "Pratiques culinaires et esprit de sacrifice", [en] M. Detienne - J.-P. Vernant, La cuisine du sacrifice en pays grec, Paris, 7-35.

Drinkwater, J. F. - Drummond, A. (1994): El mundo de los romanos, Barcelona.

Dubois-Pelerin, E. (2008): Le luxe privéà Rome et en Italie au I Ir siècle après J.-C. (=Collection du Centre Jean Bérard 29), Naples (https://doi.org/10.4000/books.pcjb.3007).

Dunbabin, K. M. (2003): The Roman Banquet: Images of Conviviality, Cambridge.

Dupont, F. (2011): "Gramática de la alimentación y de las comidas romanas", [en] Flandrin -Montanari (dirs.), 2011, 223-243.

Eliade, M. (1991): Mito y realidad, Barcelona.

Flandrin, J. L. - Montanari, M. (dirs.), (2011): Historia de la alimentación, Gijón (2a ed.).

Foxhall, L. - Forbes, H. A. (1982): " $\Sigma ı \tau o \mu \varepsilon \tau \rho \varepsilon i ́ \alpha$ Sitometría: The role of grain as a staple food in classical antiquity", Chiron 12, 41-90.

Frau Llinares, M. J. (1998): El trabajo de las mujeres. Entre la producción y la reproducción, Alicante.

Garnsey, P.

(1983): "Grain for Rome", [en] P. Garnsey - K. Hopkins - R. Whittaker (eds.), Trade in Ancient Economy, Berkeley-Los Angeles, 118-130.

(1998): Cities, Peasants and Food in Classical Antiquity. Essais in Social and Economic History, Cambridge (https://doi.org/10.1017/CBO9780511585395).

Gascó, F. (1991): “Arígnoto el pitagórico (Luciano, Philopseudes, 29ss)”, Gerión 9, 195 198.

Gowers, E. (2005): “Talking Trees: Philemon and Baucis Revisited”, Arethusa 38/3, 331-365 (https://doi.org/10.1353/are.2005.0014).

Graf, F. (2002): “Myth in Ovid", [en] Hardie (ed.), 2002, 108-120 (https://doi.org/10.1017/ CCOL0521772818.009).

Guillén, J. (1986): Vrbs Roma. Vida y costumbres de los romanos. II. La vida pública, Salamanca.

Guthrie, W. K. C. (1984): Historia de la filosofía griega. I. Los primeros presocráticos y los pitagóricos, Madrid.

Hamilton, E. (1976): La mitología, Madrid.

Hardie, Ph. (ed.), (2002): The Cambridge Companion to Ovid, Cambridge (https://doi. org/10.1017/CCOL0521772818).

Harris, M. (2009): Bueno para comer. Enigmas de alimentación y culturas, Madrid. Hindess, B. - Hirst, P. Q. (1977): Los modos de producción precapitalistas, Barcelona.

Hopkins, K. (1981): Conquistadores y esclavos, Barcelona. 
Kehoe, D. (1997): “Investimento e sicurezza del possesso nell'affitto agrario romano", [en] Lo Cascio (cur.), 1997, 61-73.

Kolendo, J. (1991): "El campesino", [en] A. Giardina (ed.), El hombre romano, Madrid, 227-256.

Lazzeroni, R. (1988): “Il nettare e l'ambrosia: su alcune rappresentazioni indoeuropee della norte", SSL 18, 177-199.

Lejavitzer, A. (2008): "La tríada mediterránea de la alimentación. El aceite, el pan y el vino en el De re coquinaria de Apicio", Estudios avanzados 10, 111-124.

Lo Cascio, E. (cur.), (1997): Terre, propietari e contadini dell'impero romano. Dall'affitto agrario al colonato tardoantico (=Nuova Italia Scientifica. Ricerche 15), Roma.

López Medina, $\mathrm{M}^{\mathrm{a}} \mathrm{J}$.

(2008): "El trabajo de las mujeres en las unidades domésticas campesinas del Sureste peninsular de época romana", [en] T. Escoriza Mateu - Ma J. López Medina - A. Navarro Ortega (eds.), Mujeres y Arquelogía. Nuevas aportaciones desde el materialismo histórico. Homenaje al Prof. Manuel Carrilero, Granada, 199-250.

(2009-2010): "Diana y otras criaturas de la noche en las Metamorfosis de Ovidio", ARYS 8, 101-128.

Mangas, J. - Álvarez, A. - Benítez, R. (2013-2014): “Casa/Casae en el Occidente Romano”, Hispania Antiqua 37-38, 271-298.

Mayer, M. (1993): "Hedyphagetica”, [en] Convivium: el arte de comer en Roma, Mérida, 15-31.

Molina Vidal, J. (2013): “Utilitas frente a Venustas: viviendas populares de la antigua Roma”, [en] S. Gutiérrez Lloret - I. Grau Mira (eds.), De la estructura doméstica al espacio social. Lecturas arqueológicas del uso social del espacio, Alicante, 127-140.

Montero, S. (2004): "El consumo de aves en la Roma de Augusto: luxus y nefas", 'Ilu. Revista de Ciencias de las Religiones, Anejos XII, 47-60.

Muñoz Llamosas, V. (1998): "Néctar y Ambrosía: atravesar la muerte”, 'Ilu. Revista de Ciencias de las Religiones 3, 147-160.

Narotzky, S. (2004): Antropología económica. Nuevas tendencias, Barcelona.

Neeve, P. W. (1984): “Colon et colon partiaire”, Mnemosyne 37/1-2, 125-142 (https://doi. org/10.1163/156852584X00105).

Ramos, E. A. (2003): "Moderato de Gades: estado de la cuestión. Cronología y forma de vida", Habis 34, 149-160.

Real, C. (1992): "El vino como alimento y medicina en la sociedad romana", Fortunatae 3, 305-314.

Rosafio, P. (1993): "Rural Labour Organization in Pliny the Younger", Analecta Romana. Instituti Danici 21, 67-79.

Santapau, M. C. (2004): "Propiedad de la tierra, producción vegetal y alimentación en el ideario romano (siglos II a.C.-I d.C.). El caso de Hispania”, Iberia 7, 7-18.

Scheid, J.

(1991): La religión en Roma, Madrid.

(2007): “Le statut de la viande à Rome", Food \& History 5/1, 19-28 (https://doi.org/10.1484/ J.FOOD.1.100183).

Segal, R. A. (1999): Theorizing About Myth, Amherst, MA.

Ste. Croix, G. E. M. (1988): La lucha de clases en el mundo griego antiguo, Barcelona.

Uría, J. (1992): "El néctar y la ambrosía: nota interpretativa al Himno a Apolo (189-193)", Myrtia 7, 141-145.

Utchenko S. L. (1987): Cicerón y su tiempo, Madrid. 
Van Andringa, W. (2007): "Sacrifices, marché de la viande et pratiques alimentaires dans le monde romain", Food \& History 5/1, 11-15 (https://doi.org/10.1484/J.FOOD.1.100182).

Vera, D. (1995): "Dalla «villa perfecta» alla villa di Palladio: sulle transformazioni del sistema agrario in Italia fra Principato e Dominato (2a parte)", Estratto da ATHENAEUM, Nuova Serie 88/2, 331-356.

Veyne, P. (1992): “El Imperio romano", [en] P. Ariès - G. Duby (dirs.), Historia de la vida privada, T.I, Madrid, 29-228.

Wilkins, J. M. - Hill, S. (2006): Food in the Ancient World, Malden-Oxford. 